\title{
Management of Bile Duct Injuries: Treatment and Long-Term Results
}

\author{
D.J. Gouma H. Obertop \\ Department of Surgery, Academic Medical Center at the University of Amsterdam, The Netherlands
}

\section{Key Words}

Bile duct injury - Bile leakage - Cholecystectomy . Laparoscopic surgery $\cdot$ Biloma $\cdot$ Biliary strictures

\section{Introduction}

Only a few years after the introduction of laparoscopic cholecystectomy in the late 1980s, surgeons declared the laparoscopic procedure as the gold standard for symptomatic gallstone disease. Several studies have shown the efficacy and safety of the procedure as well as the advantages such as reduced hospital stay, earlier recovery, less intraabdominal adhesions and a better cosmetic outcome [1$3]$. More recently it has been shown that the procedure can also be performed safely as a day-care procedure [4].

There has been extensive controversy about the increased incidence of bile duct injury (BDI) after laparoscopic cholecystectomy. Injury rates as high as $2 \%$ were reported in the early 'learning' phase and more recently a decrease in BDI has been reported from different countries [5-7]. Remarkably, other papers suggested that the majority of BDI was due to surgeons who were far beyond the learning curve, as was reported many years ago for open surgery. It has therefore also been suggested that the learning curve is not only relevant for the occurrence of BDI, but that accidental injuries are partly due to failure of the technique [8].
Different mechanisms of injury have been described in the past but more recently, Cuschieri [9] preferred a more practical approach and he identified two major groups of errors, namely (1) misidentification of the anatomy of the biliary tract as being the dominant factor in around 70\% of the injuries and (2) technical errors leading to bleeding and subsequent clipping of the bile duct/artery or leading to bile leakage by inadequate clipping or traction and subsequent lateral wall injuries. Prevention of injuries is most important and different measurements have been advocated as for example the use of routine operative cholangiography [3].

Inadequate management of BDI may lead to severe complications, such as biliary peritonitis leading to sepsis and multiple organ failure in the early phase, and biliary cirrhosis during long-term follow-up, eventually leading to the need for liver transplantation [10]. Not all forms of diagnostic work-up and treatment are available in all hospitals and there should be a low barrier for referral. The management of these patients should ideally be performed/discussed in a multidisciplinary team consisting of gastroenterologists, radiologists and surgeons. Unfortunately, lesions will occur, but suboptimal treatment of BDI is not acceptable nowadays.

The Academic Medical Center (AMC) is a referral center for HPB surgery and in this review several aspects of BDI, treatment and long-term outcome will be discussed.

\begin{tabular}{ll}
\hline KARGER & (c) 2002 S. Karger AG, Basel \\
0253-4886/02/0192-0117\$18.50/0 \\
$\begin{array}{l}\text { Fax +4161306 1234 } \\
\begin{array}{l}\text { E-Mail karger@karger.ch } \\
\text { www.karger.com }\end{array}\end{array}$ & $\begin{array}{l}\text { Accessible online at: } \\
\text { www.karger.com/journals/dsu }\end{array}$
\end{tabular}

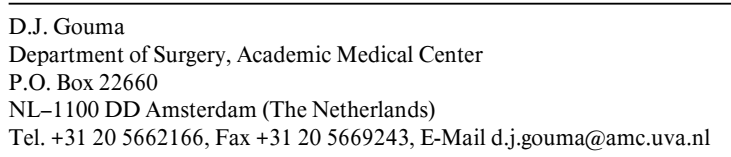




\section{Scale of the Problem}

The incidence of BDI after laparoscopic cholecystectomy varies widely in the literature. In some series, bile duct leakage from the cystic duct or the so-called duct of Lusch$\mathrm{ka}$, an intrahepatic radicle, has been excluded because it is not considered important. In other series these minor injuries are included because patients' burden is not always limited and even severe biliary peritonitis and sepsis can occur after these minor lesions. The real incidence of injuries is also influenced by the method used for data collection ranging from interview, questionnaire to wellcontrolled prospective audits providing a complete data collection $[1-3,6]$.

In two reviews the incidence after an open procedure has been reported as $0.2 \%$ [5] and $0.7 \%$ [11], whereas the incidence after laparoscopic cholecystectomy was respectively 0.81 and $0.5 \%$. One of the best studies, an audit from the West of Scotland, showed an incidence of $0.6 \%$ (including minor injuries). The incidence decreased from 0.8 to $0.4 \%$ over the years. The same results were found in a recent audit from Switzerland, a decrease to $0.3 \%$, but data are not conclusive $[6,7]$. A study from The Netherlands in the early 1990s after the start of the procedure showed an incidence of $0.8 \%[2,12]$.

At the AMC in Amsterdam, around 30-35 patients are referred yearly without any decrease during the last years, although this may reflect a change in referral pattern [13]. We still consider $0.4-0.5 \%$ mentioned in the reviews as an underestimation of the real incidence of BDI, at least in The Netherlands. The use of intraoperative cholangiography has been suggested to prevent BDI by some authors, whereas others showed no effect. Regarding the relative high numbers of referral of injuries in The Netherlands and the fact that cholangiography is generally not performed in this country, more recent data about the real incidence are needed urgently.

\section{Clinical Presentation}

Three different groups of patients can be identified according to the clinical presentation and this is mainly dependent on the time interval between the procedure, the start of the first symptoms and the detection of injury.

Injury Detected during Laparoscopic Cholecystectomy

Around $15-30 \%$ of the injuries are detected during the initial surgical procedure. Generally, biliary leakage is the first symptom, but in some patients the injuries are detected during intraoperative cholangiography, showing filling of the distal CBD with contrast into the duodenum and without filling of the intrahepatic radicals. Most patients with the diagnosis at the time of operation are treated immediately, usually after conversion to an open procedure, and only selected patients are referred to centers as patients with extensive injuries or failures after primary repair at the initial procedure and those patients with unclear lesion during exploration when the surgeon performs a temporary drainage by insertion of a drain near the duodenal ligament (fig. 1).

In our series, only $16 \%$ of the injuries were referred after detection of BDI during the procedure and this percentage has not changed over the years [13]. This low incidence may be due to the selection of patients referred for further treatment.

\section{Delayed Identification of a BDI}

The time interval between the initial laparoscopic procedure and diagnosis of a BDI varies widely in most series and in our series the median interval is 7 days [14]. Most patients referred to the AMC suffer from a delayed identification but this might be due to a patient bias. These early symptoms are generally nonspecific and consist of general malaise, nausea, vomiting, anorexia, abdominal pain and low-grade fever. The vagueness of the symptoms might probably be responsible for the delay in diagnosis. These patients were frequently discharged from hospital on the second postoperative day and re-admitted a few days later because of persistent vague abdominal complaints.

Other symptoms may become manifest later and sepsis and jaundice will eventually lead to the (delayed) detection of the injury. Patients with delayed detection of injuries are generally suffering from bile leakage resulting in a biloma and biliary peritonitis or from (sub)total occlusion of the common bile duct leading to obstructive jaundice in the early phase frequently followed by biliary leakage and biliary peritonitis due to the increasing intraductal pressure and subsequent leakage at the site of the clips after 1-2 weeks. The presenting symptoms may vary widely and are frequently not in accordance with the severity of the injury or extent of the intra-abdominal fluid/bile collection. A biloma can exist for a long period of time before symptoms occur.

In a recent study the latency time (interval between symptoms and detection) decreased to 3.5 days probably due to the fact that there is more awareness of the possibility of BDI after laparoscopic cholecystectomy among surgeons than in previous years [13]. 


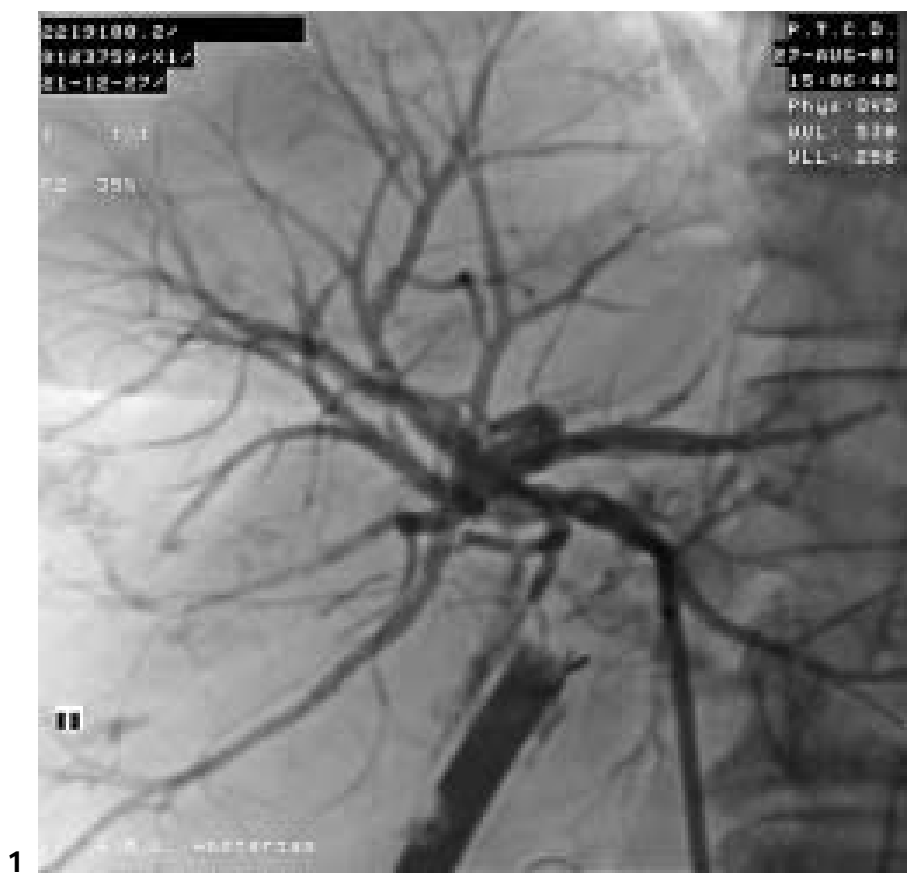

Long Symptom-Free Interval (3 Months to Even More than 1 Year)

These patients present with obstructive jaundice due to a stricture of the CBD generally without cholangitis. It has been suggested that these late bile duct strictures originate from ischemic lesions caused by extensive dissection or partial occlusion of the common duct with a clip during the initial procedure. A few patients will present with intermittent obstruction and cholangitis and these patients will frequently have a spontaneous fistula to the duodenum or colon.

\section{Diagnostic Procedures}

The first step in the diagnostic work-up of patients with abdominal complaints after laparoscopic cholecystectomy is ultrasound which can detect a fluid collection and bile duct dilatation. Subsequent percutaneous aspiration of bile will establish the diagnosis (fig. 2). Unfortunately, a fluid collection (suggesting a bile duct lesion) is still an indication for exploratory laparotomy for many surgeons without further diagnostic tests leading to unnecessary surgery to establish bile drainage or to inadequate exploration of the bile duct which may lead to extension of the lesion and subsequent negative effect on outcome. In our series, about $30 \%$ of the patients were

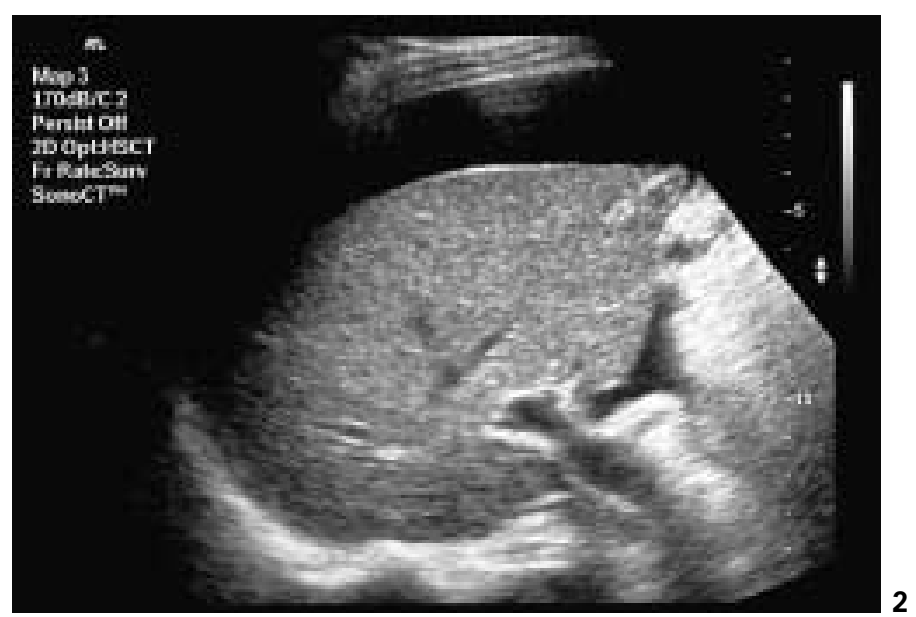

Fig. 1. A patient with biliary leakage after laparoscopic cholecystectomy. A drain was left behind and a PTD was performed to visualize the proximal biliary tract.

Fig. 2. Ultrasound of a patient with extensive fluid collection after laparoscopic cholecystectomy.

referred after one or more 'diagnostic' and mostly unnecessary explorative laparotomies. A next step should be visualization of the biliary tract by magnetic resonance cholangiopancreatography (MRCP) or ERCP, not only to establish the diagnosis, but to identify the nature and level of the lesion. If MRCP is not available and ERCP only shows the distal bile duct that is occluded by a clip (fig. 3), percutaneous transhepatic cholangiography (PTC) can be performed to visualize the proximal biliary tract, followed by percutaneous biliary drainage (fig. 1). When an abdominal drain is still in situ, cholangiography can be performed by this route (drainography). Occasionally, scintigraphy can be helpful to show leakage (fig. 4). Surgical reconstruction without visualization of the entire biliary system should not be attempted.

\section{Classification of Bile Duct Injuries}

The generally accepted Corlette-Bismuth classification for bile duct lesions relates in detail to the level of injury but not to the nature of the lesion [15]. It cannot be used for all injuries to select a treatment, especially not for bile leaks after laparoscopic surgery as well as for patients with limited stenosis of the CBD suitable for nonsurgical treatment. New classification systems for a BDI have been developed in recent years. McMahon et al. [5] suggested a 
Fig. 3. ERCP showing occlusion of the distal bile duct.
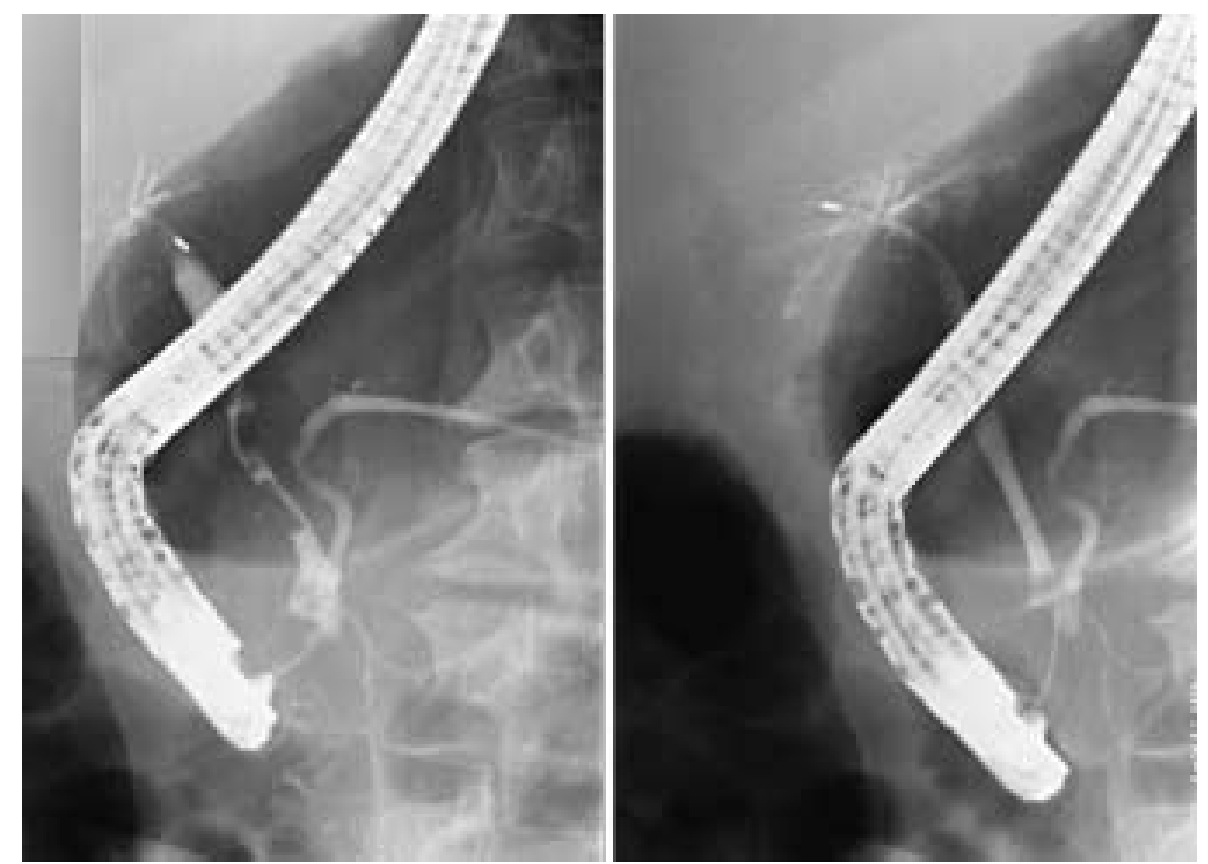

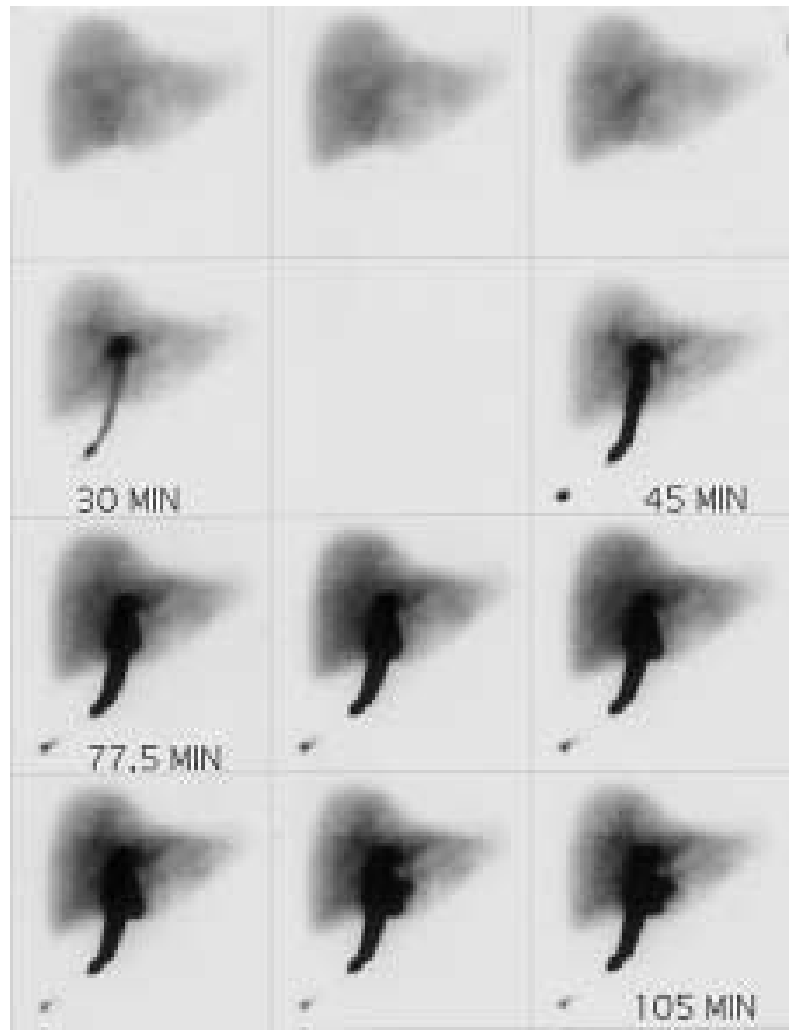

Fig. 4. Scintigraphy showing biliary leakage into the abdominal drain. The extrahepatic bile duct is not visualized suggesting a proximal lesion. division into major and minor bile duct injuries. This is helpful to differentiate the minor lesions as cystic duct leakage from major injuries of the CBD, but not to select treatment options. Therefore, Strasberg et al. [11] reported a very detailed classification (types A-E) including various subclassifications (E1-E4). This classification is very useful to select treatment by a multidisciplinary approach and to select patients who are candidates for referral to centers.

In 1993 we developed a relatively simple classification with direct implications for further treatment. In this classification, a BDI is defined as any clinically evident damage to the biliary system including the cystic duct and intrahepatic duct radicals [14]. Four types of BDI can be identified: (A) cystic duct leaks or leakage from aberrant or peripheral hepatic radicles including the so-called duct of Luschka; (B) major bile duct leaks with or without concomitant biliary strictures; (C) bile duct strictures without bile leakage, and (D) complete transection of the bile duct with or without excision of a part of the bile duct.

This classification was helpful to select treatment for patients with BDI and also useful to analyze the long-term results according to the severity/nature of a lesion. 


\section{Treatment of Injuries Detected during Laparoscopic Cholecystectomy}

The management of a BDI detected during laparoscopic cholecystectomy is mainly dependent on local expertise. If sufficient experience in hepatobiliary surgery is not available (after consultation), biliary drainage should be performed without exploration and the patient should be referred to a center. If the local anatomy is unclear, one should abandon further exploration because it could lead to proximal extension of the lesion, sacrificing of normal, healthy duct tissue, damage to the arterial supply or clipping or ligation of the (right) hepatic artery and thus will have a negative effect on the reconstruction in the near future.

With the help of an experienced surgeon, further laparoscopic or open exploration can be performed to identify the structures in the hepatoduodenal ligament and the severity of the injury. If a common bile duct lesion is adequately identified and not associated with extensive damage or tissue loss and thus suitable for primary repair, an end-to-end anastomosis should be performed over a Ttube for drainage. This procedure is associated with a high incidence of late bile duct strictures, but provides optimal internal biliary drainage with a reasonable chance for cure. It also creates the optimal circumstances for reconstructive surgery by means of an elective hepatojejunostomy at a later stage. Endoscopic stenting and/or balloon dilatation may be successful in these patients after primary repair and even if not successful does not adversely effect surgical reconstruction. If part of the bile duct is accidentally resected but the proximal duct is well below the bifurcation of the hepatic duct and local circumstances (experience) are optimal, an acute reconstruction by a hepaticojejunostomy can be performed.

\section{Treatment of a Delayed Detected Injury}

Patients with bile duct injuries, that are detected at a later phase, should not undergo exploration before classification of the injury, except in patients with severe biliary peritonitis who cannot be managed by percutaneous drainage. In patients with delayed diagnosis, drainage should be performed preferably by ERCP and stent insertion or PTC. Both techniques can be combined with USor CT-guided percutaneous drainage of a bile collection.

An important factor for surgical outcome is the timing of reconstruction. It has been suggested that surgical reconstruction by hepatojejunostomy in the 'late' acute postoperative phase (often in a patient with bile leakage and subsequent peritonitis, ileus and the presence of local inflammatory changes in the hepatoduodenal ligament) is associated with a higher risk of postoperative complications such as bile leakage and eventually stenosis of the anastomosis. Therefore, patients are sent home with a drainage catheter and collection bag and some of these patients will have a nasogastric tube or a percutaneous gastric catheter to replace bile into the duodenum. Reconstruction of the biliary tract is performed electively after 6-8 weeks. During exploration, there is generally a (dense) inflammatory reaction and fibrosis around the area of injury.

Exploration is started by mobilization of the transverse colon and duodenum from the liver, and in particular the gallbladder bed. Dissection of the hepatoduodenal ligament is essential but might be difficult due to local fibrosis. Therefore, starting dissection towards the liver hilum and early lowering of the hepatic duct remnant by dividing the hilar plate as described by Couinaud and Bismuth and recommended by Blumgart $[16,17]$ is mandatory to minimize dissection between the duct remnant and portal vein. The percutaneous drain, the drain tract, or the PTC catheter can be used as a guidance in the hilum and to the damaged duct. After puncture and opening of the proximal duct remnant, stay sutures are placed at the proximal border of the duct and the duct stump of different segmental bile duct stumps are further mobilized from the portal vein and the incision in the duct is enlarged. Multiple intrahepatic segmental duct stumps are mobilized and if possible sutured together before one or two jejunal anastomoses are performed. Usually normal duct mucosa can be seen after resection of the fibrotic tissue. Temporary stenting of the anastomosis is only performed in nondilated ducts or when a percutaneous transhepatic drainage catheter is already in situ.

\section{Long-Term Outcome}

Results from centers have shown excellent short-term results after surgical repair and long-term follow-up showed good functional outcome in more than $90 \%$ of the patients $[18,19]$.

In a recent study from our center the objective functional outcome (5 years' follow-up) was excellent in 94\% of the patients selected for endoscopic treatment. The results of surgical treatment are dependent on the timing of reconstruction. The overall success rate was $84 \%$, but for patients who underwent delayed reconstruction (after 
an interval of 6-8 weeks) $94 \%$. Despite this good objective outcome, the quality of life, even 5 years after the BDI, appeared to be severely impaired both physically and mentally in comparison to control patients who underwent laparoscopic cholecystectomy without BDI. It was frequently noted that patients were disappointed about the occurrence of the injury and in particular about the delay in diagnosis, despite their report of symptoms after the procedure, and the reluctance of the primary surgeon to discuss the procedural error and subsequent severe complication or even to acknowledge the error [20,
21]. It is known that most litigation in medical care results from failure of communication between doctor and patient rather than from the medical error itself [22]. In our series most surgeons did not discuss before the laparoscopic cholecystectomy the risk of BDI, that could lead to time-consuming procedures and referral to another hospital. This is the first study reporting impaired quality of life 5 years after treatment of BDI [23]. More studies are needed to identify factors leading to these remarkably poor results both on physical and mental subscales.

\section{References}

1 Deziel DJ, Millikan KW, Exonomou SG, Doolas A, Ko ST, Airan MC: Complications of laparoscopic cholecystectomy: A national survey of 4,292 hospitals and an analysis of 77,604 cases. Am J Surg 1993;165:9-14.

2 Go PMNYH, Schol FPG, Gouma DJ: Laparoscopic cholecystectomy in The Netherlands. Br J Surg 1993;80:1180-1183.

3 Fletcher DR, Hobbs MST, Tan P, et al: Complications of cholecystectomy: Risks of the laparoscopic approach and protective effects of operative cholangiography. A populationbased study. Ann Surg 1999;229:449-457.

4 Keulemans YCA, Eshuis J, de Haes H, de Wit LT, Gouma DJ: Laparoscopic cholecystectomy: Day-care versus clinical observation. Ann Surg 1998;228:734-740.

5 McMahon AJ, Fullarton G, Baxter JN, O'Dwyer PJ: Bile duct injury and bile leakage in laparoscopic cholecystectomy. Br J Surg 1995;82:307-313.

6 Richardson MC, Bell G, Fullarton GM: Incidence and nature of bile duct injuries following laparoscopic cholecystectomy: An audit of 5,913 cases. West of Scotland Laparoscopic Cholecystectomy Audit Group. Br J Surg 1996; 83:1356-1360.

7 Krähenbühl L, Sclabas G, Wente MN, Schäfer M, Schlumpf R, Büchler MW: Incidence, risk factors, and prevention of biliary tract injuries during laparoscopic cholecystectomy in Switzerland. World J Surg 2001;25:1325-1330.
8 Calvete J, Sabater L, Camps B, et al: Bile duct injury during laparoscopic cholecystectomy. Myth or reality of the learning curve? Surg Endosc 2000;14:608-611.

9 Shallaly GEI, Cuschieri A: Nature, aetiology and outcome of bile duct injuries after laparoscopic cholecystectomy. HPB 2000;2:3-12.

10 Loinaz C, González EM, Jiménez C, García I, Gómez R, González-Pinto I, Colina F, Gimeno A: Long-term biliary complications after liver surgery leading to liver transplantation. Word $\mathbf{J}$ Surg 2001;25:1260-1263.

11 Strasberg SM, Hertl M, Soper NJ: An analysis of the problem of biliary injury during laparoscopic cholecystectomy. J Am Coll Surg 1995; 180:101-125.

12 Schol FPG, Go PMNYH, Gouma DJ: Risk factors for bile duct injury in laparoscopic cholecystectomy: Analysis of 49 cases. Br J Surg 1994;81:1786-1788.

13 Keulemans YCA, Bergman JJGHM, de Wit LT, et al: Improvement in the management of bile duct injuries? J Am Coll Surg 1998;187: 246-254

14 Bergman JJGHM, van den Brink GR, Rauws EAJ, et al: Treatment of bile duct lesions after laparoscopic cholecystectomy. Gut 1996;38: 141-147.

15 Bismuth H: Postoperative strictures of the bile duct; in Blumgart LH (ed): The Biliary Tract. Edinburgh, Churchill Livingstone, 1982, pp 209-218.
16 Blumgart LH: Hilar and intrahepatic biliaryenteric anastomosis; in Blumgart LH (ed): Surgery of the Liver and Biliary Tract. Edinburgh, Churchill Livingstone, 1988, vol II, pp 899_ 913.

17 Bismuth H, Majno PE: Biliary strictures: Classification based on the principles of surgical treatment. World J Surg 2001;25:1241-1244.

18 Moossa AR, Easter DW, Van Sonnenberg E, Casola G, D'Agostino H: Laparoscopic injuries to the bile duct. Ann Surg 1992;215:203-208.

19 Lillemoe KD, Melton GB, Cameron JL, Pitt HA, Campbell KA, Talamini MA, Sauter PA, Coleman J, Yeo CJ: Postoperative bile duct strictures: Management and outcome in the 1990s. Ann Surg 2000;232:430-441.

20 Kern KA: Malpractice litigation involving laparoscopic cholecystectomy. Arch Surg 1997; 132:392-398.

21 Carroll BJ, Birth M, Phillips EH: Common bile duct injuries during laparoscopic cholecystectomy that result in litigation. Surg Endosc 1998;12:310-314.

22 Fischer JE: The effect of litigation on surgical practice in the USA. Br J Surg 2000;87:833834.

23 Boerma D, Rauws EAJ, Keulemans YCA, Bergman JJGHM, Obertop H, Huibregtse K, Gouma DJ: Impaired quality of life 5 years after bile duct injury during laparoscopic cholecystectomy: A prospective analysis. Ann Surg 2001;234:750-757. 